\title{
Modelling the timing of Betula pubescens budburst. I. Temperature and photoperiod: a conceptual model
}

\author{
Amelia Caffarra ${ }^{1, *}$, Alison Donnelly ${ }^{2}$, Isabelle Chuine ${ }^{3}$, Mike B. Jones ${ }^{2}$ \\ ${ }^{1}$ Research and Innovation Centre, Agriculture Area, Fondazione Edmund Mach, San Michele all'Adige, 38100 Trento, Italy \\ ${ }^{2}$ Department of Botany, School of Natural Sciences, Trinity College Dublin, Dublin 2, Ireland \\ ${ }^{3}$ CEFE-CNRS, 1919 route de Mende, 34293 Montpellier, France
}

\begin{abstract}
The main factors triggering and releasing bud dormancy are photoperiod and temperature. Their individual and combined effects are complex and change along a transition from a dormant to a non-dormant state. Despite the number of studies reporting the effects of temperature and photoperiod on dormancy release and budburst, information on the parameters defining these relationships is scarce. The aim of the present study was to investigate the effects and interaction of temperature and photoperiod on the rates of dormancy induction and release in Betula pubescens (Ehrh.) in order to develop a conceptual model of budburst for this species. We performed a series of controlled environment experiments in which temperature and photoperiod were varied during different phases of dormancy in B. pubescens clones. Endodormancy was induced by short days and low temperatures, and released by exposure to a minimal period of chilling temperatures. Photoperiod during exposure to chilling temperatures did not affect budburst. Longer exposure to chilling increased growth capability (growth rate at a given forcing temperature) and decreased the time to budburst. During the forcing phase, budburst was promoted by photoperiods above a critical threshold, which was not constant, but decreased upon longer chilling exposures. These relationships between photoperiod and temperature have, as yet, not been integrated into the commonly used processbased phenological models. We suggest models should account for these relationships to increase the accuracy of their predictions under future climate conditions.
\end{abstract}

KEY WORDS: Betula pubescens · Controlled environment experiments · Phenology · Photoperiod · Temperature $\cdot$ Dormancy $\cdot$ Budburst

\section{INTRODUCTION}

A growing number of studies worldwide have reported changes in plant and animal life cycles in response to current climate change (for reviews see Peñuelas \& Filella 2001, Parmesan \& Yohe 2003, Root et al. 2003, Menzel et al. 2006). Most of these phenological changes are highly correlated with changes in temperature, and a trend for advanced spring events (such as leaf unfolding or flowering) is apparent for many species (Sparks \& Menzel 2002, Root et al. 2003, Menzel et al. 2006).
In order to predict and attempt to mitigate the impacts of climate change, in particular rising temperature, it is crucial to understand the effect climate plays on plant growth, of which budburst is one aspect. However, the lack of understanding of the physiological mechanisms regulating dormancy makes it difficult to develop widely applicable predictive models of budburst (Hänninen 1995, Arora et al. 2003).

Experimental evidence shows that in many tree species, the main factors triggering and releasing dormancy are photoperiod and temperature (Downs \& Borthwick 1956, Murray et al. 1989, Myking \& Heide 
1995, Thomas \& Vince Prue 1997). The action of these environmental drivers is complex and changes along the transition from a dormant to a non-dormant state. In addition, it has been shown that photoperiod and temperature interact at various stages during dormancy induction, release and quiescence (Håbjørg 1972, Junttila 1980, Heide 1993, 2003, Myking \& Heide 1995, Partanen et al. 2001).

Photoperiod affects the time at which buds enter a phase of winter rest. Short days (ShDs) signal the onset of winter, which, in turn, triggers decreasing 'growth competence' (growth capability). Once the plant has been exposed to a certain number of dormancyinductive days (dormancy induction requirement), the phase of endodormancy is reached, a period during which buds do not grow even under favourable environmental conditions (Downs \& Borthwick 1956, Håbjørg 1972, Howe et al. 1996, Thomas \& Vince Prue 1997, Welling et al. 1997).

Chilling temperatures are the main trigger for endodormancy release (Perry 1971, Sarvas 1974, Cannell \& Smith 1983, Battey 2000). The concept of 'chilling temperature' is not clearly defined, and a consistent response to chilling has not been detected in dormant plants. To date, it is not known whether photoperiod plays a role in chilling fulfilment, i.e. if it affects chilling efficiency for a given temperature during endodormancy release.

After the release of endodormancy, warm temperatures stimulate growth in buds, which then enter the phase of ecodormancy, i.e. have the ability to resume growth when exposed to growth-promoting signals (forcing conditions). During this phase the rate of growth is proportional to temperature. Ecodormant buds burst upon accumulation of a certain heat requirement (Perry 1971, Hänninen 1990, Battey 2000). However, it has been shown in some species that additional chilling during this period decreases the heat requirement for budburst to occur (Nienstaedt 1966, Landsberg 1974, Couvillon \& Erez 1980, Heide 1993, Myking \& Heide 1995). Photoperiod has been found to interact with temperature during the ecodormant period. In Betula pubescens and B. pendula, long days (LDs) appear to substitute partially for the effect of low temperatures and decrease the heat requirement for budburst to occur (Myking \& Heide 1995). The response of the rate of bud growth of young seedlings to increasing temperature has a sigmoidal shape (Sarvas 1972).

Despite the number of studies reporting the effects of temperature and photoperiod on dormancy release and budburst, information on the parameters defining these relationships is scarce (Kramer 1994, Hänninen 2006). The development of a process-based model of budburst requires a quantitative description of the interactions between the factors conditioning budburst timing, and their control of the transitions from one sub-phase of dormancy to the next. The integration of these interactions in a coherent model structure can only be obtained through inter-comparable experiments linking together observed processes and measuring the rates of plant response to changes in environmental drivers (Hänninen 2006).

The aim of the present study was to investigate the effects and interaction of temperature and photoperiod on the rates of dormancy induction and release in Betula pubescens, through a set of experiments, in order to develop a conceptual model of dormancy for this species.

More specifically, we aimed: (1) to quantify the effects of photoperiod and temperature on dormancy induction requirements and determine the effect of their interactions on subsequent bud growth, (2) to quantify chilling requirements, (3) to test the interaction between photoperiod and chilling exposure on budburst rate and percentage, (4) to parameterise the sigmoidal function describing the rate of budburst at different forcing temperatures and (5) to integrate these experimental results with previous findings in order to develop a conceptual model of dormancy, which has been mathematically formalized (Caffarra et al. 2011, this issue)

The present study was conducted on Betula pubescens (birch) because it is widely distributed at boreal and temperate latitudes (Atkinson 1992), where climate is warming more rapidly than in other regions (IPCC 2007). Alteration in the phenology of B. pubescens is thus likely and may have important consequences for ecosystem dynamics in these regions.

\section{MATERIALS AND METHODS}

\subsection{Selection and vegetative propagation of the experimental material}

The experiments were conducted on the Betula pubescens (Ehrh.) (birch) clone grown in the International Phenological Gardens (IPGs) network, which comprises 89 garden sites throughout Europe (www. agrar.hu-berlin.de/struktur/institute/nptw/agrarmet/ phaenologie/ipg/ipg_allg-e). The clone under study, originally from Germany, was propagated vegetatively, in order to obtain experimental material with a homogenous genotype, and therefore any observed differences could be attributed to environmental conditions rather than genotypical differences among plants. The clones in the current experiments were propagated using softwood cuttings, taken from the soft, new growth of the tree, as described by Hartmann 
et al. (1997). In 2003 we took 300 softwood cuttings from the $B$. pubescens IPG clone growing at the John Fitzgerald Kennedy Arboretum in Wexford (Ireland, IPG No.14). After collection, the softwood cuttings were treated with rooting powder $(0.4 \%$ 1-naphthaleneacetic acid, NAA) and placed in compost-filled trays before being transferred to a mist unit until rooting took place (approximately 6 wk later). The rooted cuttings were potted in 11 pots with John Innes No. 3 compost. The same procedure was followed in 2004.

\subsection{Experimental designs}

During the course of 2003 (Year 1), 2004 (Year 2) and 2005 (Year 3), 4 experiments were performed on the propagated clones of Betula pubescens (Table 1). The experiments were designed to investigate the primary effects and interactions of temperature and photoperiod during the different phases of bud development and growth on the timing and percentage of budburst (BBCH Scale Phase 09: green shoot tips clearly visible). Observations were recorded every 2 or $3 \mathrm{~d}$ following the initiation of forcing conditions, for a period of $80 \mathrm{~d}$. The experiments were divided into 3 sequential phases, referred to as 'dormancy induction', 'chilling' and 'forcing'. The actual physiological transitions occurring as a result of these combinations of treatments were inferred through observation of the subsequent budburst responses. A summarised description of the experiments, including their aims and underlying hypotheses, is shown in Table 1 . The experiments were conducted either on sets of rooted shoots or on sets of cuttings, each containing 1 bud, taken from the central portion of the branches of the clones and cut into 3-5 cm long segments. These 1node cuttings were protected with Parafilm at their distal end, to prevent water loss and desiccation, and placed in compost-filled trays before being transferred into experimental conditions. The experimental material was watered regularly, and the compost remained moist at all times. All treatments that took place in the growth cabinets (Sanyo Fitotron 6001 Sanyo-Gallenkamp and Fisons Fitotron 600H, Fisons Scientific) received a photon flux density of $170 \pm$ $10 \mu \mathrm{mol} \mathrm{m} \mathrm{m}^{-2} \mathrm{~s}^{-1}$, with a red/far red ratio varying between 7 and 9 (quantum sensor: Li-Cor) unless otherwise indicated. The treatments that took place in the heated glasshouse received natural day length and an average temperature of about $15^{\circ} \mathrm{C}$, but never falling below $12^{\circ} \mathrm{C}$. Temperature was recorded daily with a datalogger or manually using a max./min. thermometer. Daily maximum and minimum temperatures in outdoor treatments were recorded by a nearby weather station.

\subsection{Manipulations}

\subsubsection{Expt $1-$ Effects of forcing temperature}

On 28 February of Year 1, 60 dormant twigs of Betula pubescens were removed from the parent plant, which was growing outdoors in IPG 14. Thus, up to that date, the twigs had been exposed to natural chilling. After collection, the twigs were stored in the dark at $3^{\circ} \mathrm{C}$ for $16 \mathrm{~d}$, until the start of the experiment (16 March). By this time, the plant's chilling requirement was assumed to have been met. Each twig was cut into a 1-node cutting. The 60 one-node cuttings were split into replicate sets of 10 and transferred into 5 growth cabinets set at $6,12,18,24$ and $32^{\circ} \mathrm{C}$ and an incubator (described by Clifton-Brown \& Jones 1999 ) set at $-3^{\circ} \mathrm{C}$, maintained at a 16 h light photoperiod.

\subsubsection{Expt 2-Effects of chilling duration and forcing photoperiod}

We tested the effects of a range of forcing photoperiods on Betula pubescens budsticks removed from rooted shoots at various stages of chilling accumulation. In late November of Year 2, 10 one-year old IPG clones of $B$. pubescens, kept in a heated greenhouse, were placed outdoors to receive natural chilling. After chilling durations of $0,30,55$, or $95 \mathrm{~d}, 9$ budsticks were removed from the tree branches, and each was cut into 4 one-node cuttings. The budsticks were randomly selected from random trees, which meant that a tree could be selected more than once at each sampling time. Then, the budsticks were placed in compost-filled trays and immediately transferred to 4 growth cabinets at $22^{\circ} \mathrm{C}$ with $10,12,14$, or $16 \mathrm{~h}$ photoperiods. Each of the 16 treatments, i.e. 4 chilling durations $\times 4$ forcing photoperiods, was applied to a replicate set of 9 cuttings. Additionally, the fully chilled, rooted plants that were used for budstick sampling were grown in growth cabinets in the same forcing conditions as those tested on the cuttings $\left(22^{\circ} \mathrm{C}\right.$ with $10,12,14$, or $16 \mathrm{~h}$ photoperiods $)$ and monitored for 9 mo to establish the critical photoperiod for growth cessation.

2.3.3. Expt 3-Effects of dormancy induction temperature and duration, chilling photoperiod and chilling presence/absence

We tested the effect on budburst of high $\left(18^{\circ} \mathrm{C}\right)$ and low $\left(10^{\circ} \mathrm{C}\right)$ temperatures during dormancy induction, for 2 different durations (30 or $60 \mathrm{~d}$ ), and the effect of photoperiod (short: $8 \mathrm{~h}$, and total darkness: $0 \mathrm{~h}$ ) during 


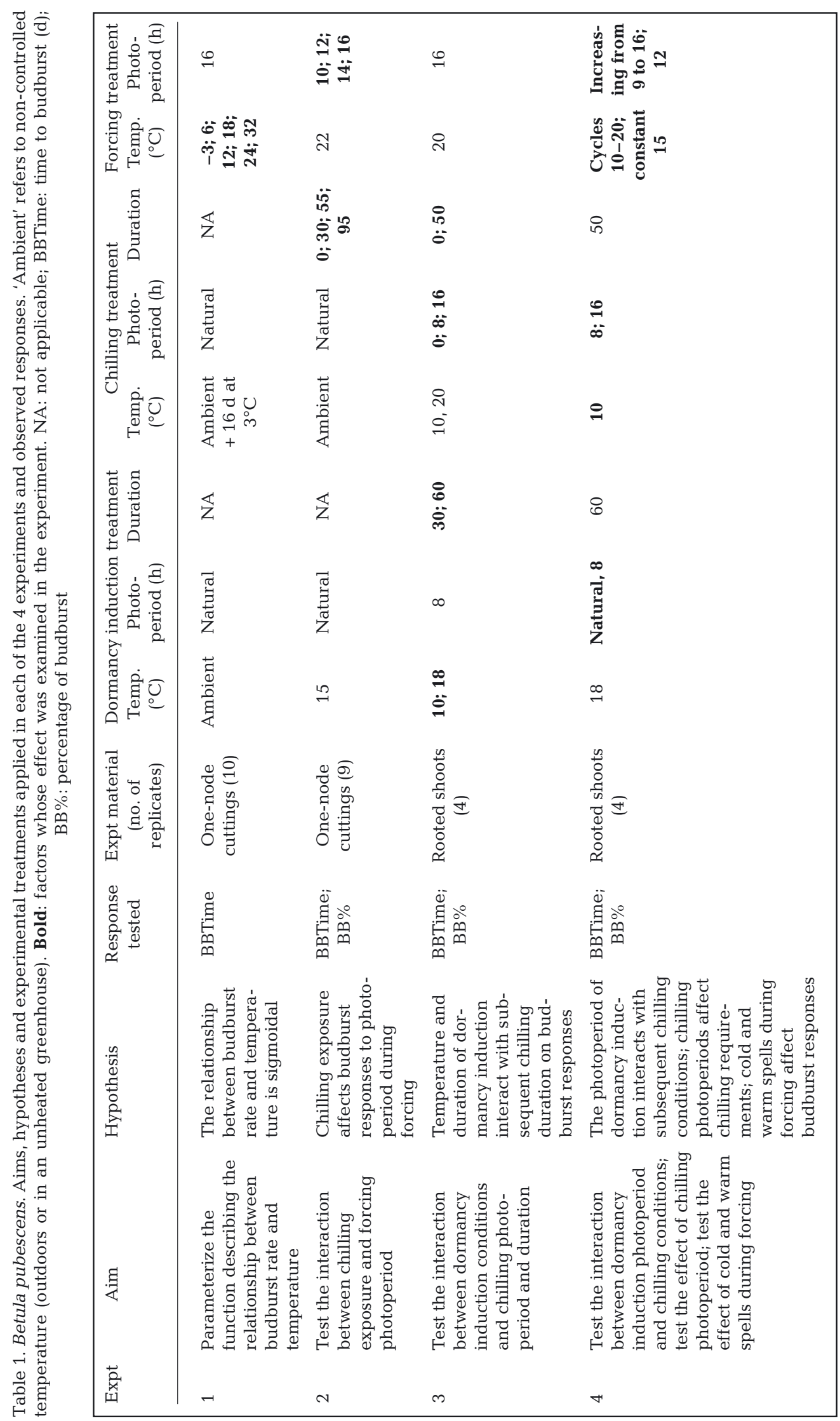


endodormancy. The chilling treatments included a control treatment at a high temperature and with a long photoperiod, used to determine whether the plants were actually endodormant. On 19 July of Year 3, 48 one-year old IPG clones of Betula pubescens were divided into 2 equal groups that were placed in each of 2 growth cabinets where they received dormancy induction at a constant temperature of $10^{\circ} \mathrm{C}$ (24 plants, first group) or $18^{\circ} \mathrm{C}(24$ plants, second group). Half of each group (12 plants) remained in the growth cabinet for $30 \mathrm{~d}$ (short dormancy induction) and the other half for $60 \mathrm{~d}$ (long dormancy induction). During this time the photoperiod was maintained at $8 \mathrm{~h}$. Immediately after each of the 2 dormancy induction treatments, each of these 12-plant groups was divided into 3 groups of 4 plants each and received (1) a $50 \mathrm{~d}$ long chilling treatment at $10^{\circ} \mathrm{C}$, with an $8 \mathrm{~h}$ photoperiod, or (2) with a $0 \mathrm{~h}$ photoperiod (chilled treatments), or (3) $50 \mathrm{~d}$ at $20^{\circ} \mathrm{C}$ with a $16 \mathrm{~h}$ photoperiod (control treatment). At the end of each treatment plants were transferred into forcing conditions at $20^{\circ} \mathrm{C}$ with a $16 \mathrm{~h}$ photoperiod. Each of the 12 treatments, i.e. 2 dormancy induction temperatures $\times 2$ dormancy induction durations $\times 3$ chilling treatments, was applied to a replicate set of 4 plants.

2.3.4. Expt 4 - Effects of temperature and photoperiod during the dormancy induction, chilling and forcing phases

A total of 64 one-year old IPG clones of Betula pubescens were tested in an incomplete factorial experiment involving the manipulation of photoperiod and temperature during 3 different phases: dormancy induction, endo- and eco-dormancy. This experiment was designed to investigate: (1) the effects of naturally decreasing photoperiod versus constantly short photoperiods during the phase of dormancy induction, (2) the effect of photoperiod ( 8 vs. 16 h) during chilling and (3) the effect of cold and warm spells during forcing, on budburst timing. In July of Year 3, 32 plants were moved to growth cabinets, where they were kept for $60 \mathrm{~d}$ in dormancy-inductive conditions ( $8 \mathrm{~h}$ photoperiod at $18^{\circ} \mathrm{C}$ ). The other 32 plants remained in the greenhouse, where they received natural daylength and an average daily temperature of about $18^{\circ} \mathrm{C}$. During this period, daylength decreased naturally from 15.7 to $12.2 \mathrm{~h}$. On 17 September, each set of 32 plants was divided into 2 groups of 16 plants, each receiving the following chilling treatments for $50 \mathrm{~d}$ : (1) $8 \mathrm{~h}$ photoperiod at $10^{\circ} \mathrm{C}$ and (2) $16 \mathrm{~h}$ photoperiod at $10^{\circ} \mathrm{C}$. Subsequently each set of 16 plants was divided into 4 groups of 4 plants, which were placed in 4 different forcing treatments. Three of the treatments were exposed to gradu- ally increasing photoperiods. In these treatments photoperiods were maintained constant for $4 \mathrm{~d}$ periods, but were gradually increased from 9 to $16 \mathrm{~h}$ over a period of $32 \mathrm{~d}$. Over the $32 \mathrm{~d}$ period of lengthening photoperiods, these 3 treatments also received a series of cold and warm spells as follows: (1) alternation of warm $\left(20^{\circ} \mathrm{C}\right)$ and cold $\left(10^{\circ} \mathrm{C}\right)$ spells lasting $8 \mathrm{~d},(2)$ alternation of cold $\left(10^{\circ} \mathrm{C}\right)$ and warm $\left(20^{\circ} \mathrm{C}\right)$ spells lasting $8 \mathrm{~d}$, in phase opposition to the first treatment, so as to correspond to different daylengths, and (3) alternation of warm $\left(20^{\circ} \mathrm{C}\right)$ and cold $\left(10^{\circ} \mathrm{C}\right)$ spells lasting $4 \mathrm{~d}$. The fourth forcing treatment received (4) constant photoperiod and temperature, i.e. a $12 \mathrm{~h}$ photoperiod at $15^{\circ} \mathrm{C}$. Each of the 16 treatments, i.e. 2 dormancy induction photoperiods $\times 2$ chilling treatments $\times 4$ forcing treatments, was applied to a replicate set of 4 plants.

\subsection{Statistical analyses}

We analysed the response of budburst timing and percentage of budburst to the environmental factors that were varied in each experiment. When rooted shoots were used in the experiments, we analysed their mean time to budburst, which was obtained by averaging the number of days to budburst of each bud (arithmetic mean). When budsticks were used, the number of days to budburst of each budstick was considered. The count of the number of days to budburst was started from the moment of transfer into the forcing treatment. Budburst percentage in rooted shoots was defined as the percentage of buds bursting against the total number of buds on the shoots. For 1-node budsticks budburst percentage was either 0 (nonflushing) or $100 \%$ (flushing). When the data for budburst percentage were affected by the loss of experimental material due to desiccation, only the data for budburst timing of healthy buds were used. The rate of forcing (FR) (of interest for its use in phenological models) was obtained by normalising the mean budburst rates measured in Expt 1 (1/mean time to budburst) to 1 at $32^{\circ} \mathrm{C}$ and fitting these data with a sigmoidal curve of the following equation:

$$
\operatorname{FR}(t)=\frac{1}{1+\mathrm{e}^{a\left(T_{\mathrm{m}}-b\right)}}
$$

where $T_{\mathrm{m}}$ stands for temperature and $a$ and $b$ are parameters expressing the slope and inflection point of the curve, respectively. The significance of estimated parameters was determined by a $t$-test.

The data were subjected to 1-way and factorial analysis of variance (ANOVA) to check for significant differences among the means of the days to budburst and budburst percentages measured in the different treatments. Experimental designs with unequal sam- 
ple sizes were analysed with Type III sum of squares, as suggested by Quinn \& Keough (2002). Unbalanced designs with empty cells were analysed by selecting subsets of the data with observations in all cells in order to test 'balanced' hypotheses for lower-order effects (Quinn \& Keough 2002) and by grouping factors together in order to avoid the calculation of interaction effects among factors with incomplete levels. Data from the experiments were tested for deviance from normality and for the homogeneity of variance using Fligner-Killeen's and Levene's tests (Quinn \& Keough 2002). These assumptions were met in Expts 1 and 4, but no homogeneity of variance was found in Expts 2 and 3 (Levene test; $\mathrm{p}<0.05$ ). Since, according to Lindman (1974), the F-statistic is robust against this violation when no significant correlations between means and their variances exist across the cells of the design (Spearman correlation; Expt 2: $\mathrm{R}=0.38, \mathrm{p}>0.05$; Expt $3: \mathrm{R}=0.01, \mathrm{p}>0.05$ ), parametric statistics were used throughout the entire study.

\section{RESULTS}

\subsection{Expt 1}

Forcing temperature had a significant effect on the time to budburst $(p<0.001)$, with higher forcing temperatures advancing budburst. Times to budburst ranged between $2.1 \mathrm{~d}$ at $32^{\circ} \mathrm{C}$ and $12.1 \mathrm{~d}$ at $6^{\circ} \mathrm{C}$. No budburst was observed at $-3^{\circ} \mathrm{C}$. The relationship between the rate of forcing and temperature showed a highly significant sigmoidal pattern (the $t$-test on model parameters yielded values of $p<0.01$ ) (Fig. 1).

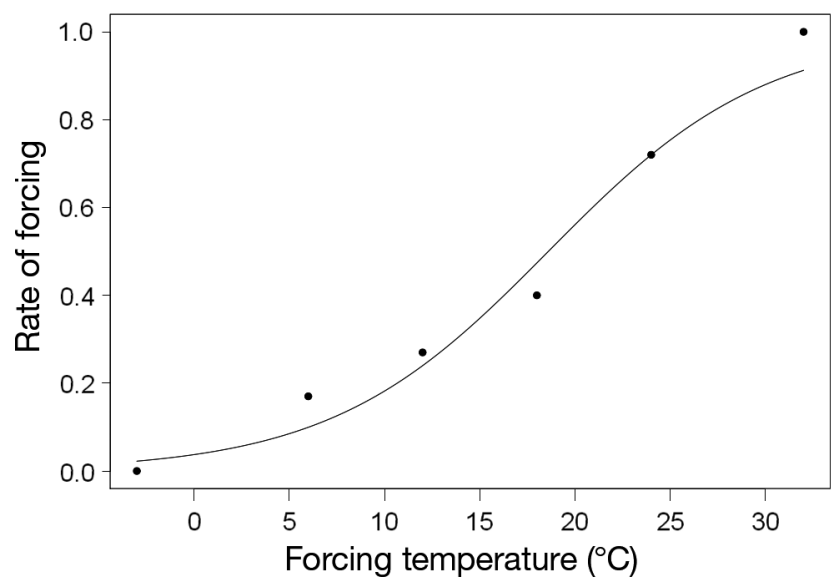

Fig. 1. Betula pubescens. Relationship between forcing rate (mean budburst rates normalised to 1 at $32^{\circ} \mathrm{C}$ ) and mean forcing temperature. The relationship was fitted with a sigmoidal curve with the equation: rate of budburst $=1 / 1+\mathrm{e}^{0.174\left(T_{\mathrm{m}}-18.5\right)}$, where $T_{\mathrm{m}}$ is temperature in the forcing treatments

\subsection{Expt 2}

Buds exposed to longer chilling duration showed a significant decrease in the time to budburst and a significant increase in the percentage of budburst (Tables $2 \& 3$ ).

The forcing photoperiod had a significant effect on budburst percentage and an almost significant effect $(p=0.051)$ on the time to budburst (Table 2). Longer photoperiods during the forcing period increased the percentage of budburst and decreased the time to budburst. There was also an interaction between chilling duration and the subsequent forcing photoperiod on the percentage of budburst (Table 2). The critical photoperiod promoting bud growth during forcing decreased with increasing exposure to chilling. This critical photoperiod decreased from $12-14 \mathrm{~h}$ for unchilled buds to $10 \mathrm{~h}$ or less for buds exposed to $95 \mathrm{~d}$ of natural chilling (Table 3). After the longest chilling treatment $(95 \mathrm{~d})$, the rooted trees used for this experiment were transferred to the growing cabinets with the cuttings (1 plant in the $10 \mathrm{~h}$ photoperiod, 3 plants in each of the 12,14 and $16 \mathrm{~h}$ photoperiods) to check their critical dormancy induction photoperiod. After resuming vegetative growth, the trees kept growing at photoperiods above 12-14 $\mathrm{h}$, but entered dormancy after 3-4 mo when grown at photoperiods below $12-14 \mathrm{~h}$.

\subsection{Expt 3}

Expt 3 showed a significant interaction between dormancy induction duration or temperature and exposure to chilling on the percentage of budburst (Table 4). Exposure to low temperature during dormancy induction increased the percentage of budburst in chilled compared to unchilled plants (Fig. 2). When considering only chilled plants, dormancy induction temperature and duration were found to have a significant effect on both timing and percentage of budburst (Table 4). Lower dormancy induction temperature decreased the time to budburst and increased the percentage budburst in subsequently chilled plants (mean percentage of budburst increasing from 37 to $61 \%$ and mean time to budburst decreasing from 25 to $21 \mathrm{~d}$, when comparing the 10 and $18^{\circ} \mathrm{C}$ treatments). Longer dormancy induction duration had the same general effect, with mean percentage of budburst increasing from 20 to $70 \%$ and mean time to budburst decreasing from 27 to $20 \mathrm{~d}$, as dormancy induction was extended from 30 to $60 \mathrm{~d}$.

In line with Expt 2, budburst percentage and timing were significantly affected by exposure to chilling temperatures (Table 4). In addition, there was significant interaction between exposure to chilling and dormancy induction conditions. Exposure to chilling de- 
Table 2. Betula pubescens. Analysis of variance of the time to budburst and the percentage of budburst in Expt 2

\begin{tabular}{|lrrrrrrr|}
\hline \multirow{2}{*}{ Source of variation } & \multicolumn{4}{c}{ Time to budburst } & \multicolumn{4}{r|}{ Percentage of budburst } \\
& df & $F$ & p & df & $F$ & p \\
\hline Chilling duration $(\mathrm{ChD})$ & 2 & 14.16 & $<0.001$ & 3 & 19.25 & $<0.001$ \\
Forcing photoperiod (FPht) & 2 & 3.18 & 0.051 & 3 & 10.91 & $<0.001$ \\
$\mathrm{ChD} \times$ FPht & 4 & 1.09 & 0.374 & & 9 & 2.13 & 0.032 \\
\hline
\end{tabular}

Table 3. Betula pubescens. Means and standard errors for the number of days to budburst and percentage of budburst in Expt 2

\begin{tabular}{|lccc|}
\hline $\begin{array}{l}\text { Chilling } \\
\text { duration (d) }\end{array}$ & $\begin{array}{c}\text { Forcing } \\
\text { photoperiod (h) }\end{array}$ & $\begin{array}{c}\text { Days to } \\
\text { budburst }\end{array}$ & $\begin{array}{c}\text { Budburst } \\
(\%)\end{array}$ \\
\hline 0 & 10 & & $0.0 \pm 0.0$ \\
& 12 & & $0.0 \pm 0.0$ \\
& 14 & $18.3 \pm 2.7$ & $37.5 \pm 18.3$ \\
30 & 16 & $21.3 \pm 6.0$ & $33.3 \pm 16.7$ \\
& 10 & & $0.0 \pm 0.0$ \\
& 12 & $23.7 \pm 1.3$ & $33.3 \pm 16.7$ \\
55 & 14 & $18.0 \pm 2.1$ & $37.5 \pm 18.3$ \\
& 16 & $17.5 \pm 0.4$ & $44.4 \pm 17.6$ \\
& 10 & & $0.0 \pm 0.0$ \\
95 & 12 & $15.8 \pm 0.5$ & $44.4 \pm 17.6$ \\
& 14 & $16.8 \pm 0.7$ & $100.0 \pm 0.0$ \\
& 16 & $17.8 \pm 1.0$ & $77.8 \pm 14.7$ \\
& 10 & $8.3 \pm 0.7$ & $77.8 \pm 14.7$ \\
& 12 & $7.9 \pm 0.8$ & $100.0 \pm 0.0$ \\
& 14 & $7.3 \pm 0.7$ & $100.0 \pm 0.0$ \\
& 16 & $7.8 \pm 0.8$ & $100.0 \pm 0.0$ \\
\hline
\end{tabular}

creasing photoperiod (52\% and $40 \mathrm{~d})$. In line with Expt 3, the photoperiod received during the chilling treatment had no significant effect on either budburst percentage or timing (Table 5). The application of cold and warm spells during forcing did not affect the time to budburst compared to average temperature (Table 5).

\section{DISCUSSION}

The results from Expt 2 suggest that in ecodormant buds, the interactions between photoperiod and previous chilling exposure are more complicated than previously thought. Various studies have shown an interaction between photoperiod and duration of exposure to chilling conditions on budburst timing (Heide 1993, Myking \& Heide 1995, Partanen et al. 2005), in which LDs promoted growth in birch after partial chilling exposure. Myking \& Heide (1995) hypothesised that LDs acted as a substitute for chilling in partially chilled plants. However, our results showed that the critical growth-promoting photoperiod in partially chilled birch buds was not constant, but decreased upon increasing chilling exposure. In addition, the photoperiod received during the chilling treatment $\left(\right.$ at $\left.10^{\circ} \mathrm{C}\right)$ was found to have no effect on creased budburst percentage and increased time to budburst in birch plants exposed to short and warm dormancy induction, while it increased budburst percentage and decreased time to budburst in birch plants receiving long or cold dormancy induction.

The photoperiod received during the chilling treatment had no significant effect on either budburst percentage or timing (Table 4).

\subsection{Expt 4}

In Expt 4, the photoperiod during the phase of dormancy induction had a significant effect on the timing and percentage of budburst (Table 5). A larger percentage of budburst and a shorter time to budburst were observed in plants exposed to a constant, short photoperiod during dormancy induction ( $78 \%$ and $34 \mathrm{~d})$, compared to those that received a naturally de-
Table 4. Betula pubescens. Effect of dormancy induction temperature, and chilling photoperiod and duration. ANOVA of the time to budburst and the percentage of budburst (Expt 3) for all data and for a subset of chilled plants. Due to the missing data for time to budburst in non-flushing plants, dormancy induction duration (DID) and temperature (DIT) were grouped into a single factor (DID + DIT) with 4 levels. A subset of 3 of these levels, with observations in all cells, was analysed: 1 . DID $=30 \mathrm{~d}$ and DIT $=10^{\circ} \mathrm{C} ; 2$. DID $=60 \mathrm{~d}$ and DIT $=10^{\circ} \mathrm{C}$; 3. $\mathrm{DID}=60 \mathrm{~d}$ and $\mathrm{DIT}=18^{\circ} \mathrm{C}$

\begin{tabular}{|c|c|c|c|c|c|c|}
\hline \multirow[t]{2}{*}{ Source of variation } & \multicolumn{3}{|c|}{$\begin{array}{l}\text { Time to } \\
\text { budburst }\end{array}$} & \multicolumn{3}{|c|}{$\begin{array}{l}\text { Percentage of } \\
\text { budburst }\end{array}$} \\
\hline & $\mathrm{df}$ & $F$ & $\mathrm{p}$ & $\mathrm{df}$ & $F$ & $\mathrm{p}$ \\
\hline \multicolumn{7}{|l|}{ All data } \\
\hline Dormancy induction duration (DID) & 1 & 0.68 & 0.417 & 1 & 5.55 & 0.024 \\
\hline Dormancy induction temperature (DIT) & 1 & 0.61 & 0.442 & 1 & 0.01 & 0.923 \\
\hline Chilling presence/absence (Chill) & 1 & 0.91 & 0.349 & 1 & 24.94 & $<0.001$ \\
\hline $\mathrm{DID} \times \mathrm{DIT}$ & 1 & 0.07 & 0.797 & 1 & 2.19 & 0.147 \\
\hline DID $\times$ Chill & 1 & 0.88 & 0.357 & 1 & 51.58 & $<0.001$ \\
\hline DIT $\times$ Chill & 1 & 4.64 & 0.041 & 1 & 14.54 & $<0.001$ \\
\hline DID $\times$ DIT $\times$ Chill & 1 & 0.58 & 0.454 & 1 & 3.85 & 0.057 \\
\hline \multicolumn{7}{|l|}{ Chilled plants } \\
\hline DID & 1 & 7.89 & 0.011 & & 115.71 & $<0.001$ \\
\hline DIT & 1 & 4.80 & 0.040 & 1 & 19.60 & $<0.001$ \\
\hline Chilling photoperiod (ChPht) & 1 & 2.62 & 0.125 & 1 & 2.00 & 0.169 \\
\hline $\mathrm{DID} \times \mathrm{DIT}$ & 1 & 0.64 & 0.433 & 1 & 0.30 & 0.610 \\
\hline $\mathrm{DID} \times \mathrm{ChPht}$ & & & & 1 & 0.80 & 0.373 \\
\hline $\mathrm{DIT} \times \mathrm{ChPht}$ & & & & 1 & 0.50 & 0.493 \\
\hline Dormancy induction treatment (DID + DIT) & 2 & 8.33 & 0.003 & & & \\
\hline ChPht $\times(\mathrm{DID}+\mathrm{DIT})$ & 2 & 5.04 & 0.020 & & & \\
\hline
\end{tabular}




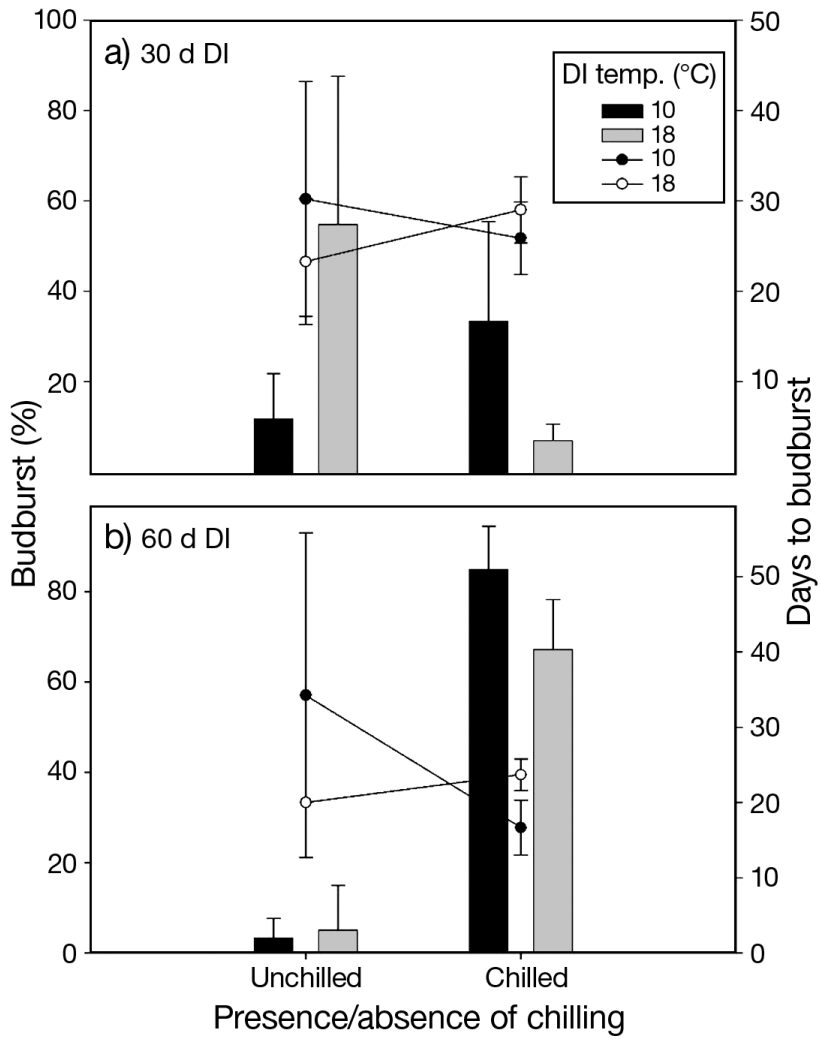

Fig. 2. Betula pubescens. Effect of dormancy induction (DI) temperature and duration and exposure to chilling temperatures on bud phenology of $B$. pubescens. Mean percentage budburst (bar plot) and mean number of days to budburst (line and scatter plot) in chilled and unchilled B. pubescens exposed to DI durations of: (a) $30 \mathrm{~d}$ and (b) $60 \mathrm{~d}$, and temperatures of 10 and $18^{\circ} \mathrm{C}$. Data are from Expt 3. Error bars: standard errors of the mean

Table 5. Betula pubescens. Effect of dormancy induction photoperiod, chilling photoperiod and warm/cold spells applied during forcing. ANOVA of the time to budburst and percentage of budburst (Expt 4) for dormancy induction and chilling factors and forcing factors. Percentage of budburst was arcsine transformed to homogenise variance. Due to missing blocks, caused by either the experimental design or the absence of budburst in some treatments, only subsets of data without missing observations were analysed

\begin{tabular}{lrrrrrrr} 
Source of variation & \multicolumn{3}{c}{$\begin{array}{c}\text { Time to } \\
\text { budburst }\end{array}$} & \multicolumn{3}{c}{$\begin{array}{c}\text { Percentage of } \\
\text { budburst }\end{array}$} \\
& df & $F$ & $p$ & df & $F$ & $p$ \\
\hline Dormancy induction and chilling factors & & & & & & & \\
Dormancy induction photoperiod (DIPht) & 1 & 21.50 & 0.009 & 1 & 18.71 & $<0.001$ \\
Chilling photoperiod (ChPht) & 1 & 0.27 & 0.640 & 1 & 0.07 & 0.786 \\
DIPht $\times$ ChPht & 1 & 0.08 & 0.780 & 1 & 0.08 & 0.777 \\
& & & & & & & \\
Forcing factors & & & & & & \\
Cycle duration & 1 & 0.59 & 0.453 & 1 & 0.63 & 0.438 \\
Cycle timing & 1 & 1.08 & 0.309 & 1 & 0.93 & 0.347 \\
Cold/Warm spell cycles & 1 & 3.29 & 0.080 & 1 & 3.16 & 0.090
\end{tabular}

budburst, indicating that chilling efficiency relies exclusively on temperature. Thus, chilling acted quantitatively on birch photoperiod sensitivity, rather than the reverse. Previous attempts to integrate photoperiod into models of budburst have introduced daylength as an additive or multiplicative factor affecting the rate of chilling (Campbell \& Sugano 1975, Kramer 1994). However, our results suggest that photoperiod sensitivity should be represented through a chilling-dependent function affecting the rate of forcing, rather than a photoperiod-dependent function affecting the rate of chilling. This changing photoperiod sensitivity seems different from the induction of dormancy by $\mathrm{ShD}$, in which critical photoperiod is a constant trait under genetic control (Frewen et al. 2000). This effect should be integrated into predictive models of budburst, as it may improve their realism and accuracy. It could become important for scenarios in which milder winters do not completely fulfil the plant's chilling requirements.

The large variation in both the time to budburst and percentage budburst for partially chilled treatments is striking, given the homogeneous environmental and genotypical conditions of each treatment. This variation is due to phenological asynchrony among clones, as can be seen in Table 5 (standard errors of the means of Expt 2) and in Fig. 2 (error bars for unchilled treatments and short dormancy induction treatments of Expt 3). Such large variation in budburst timing and percentage might be an effect of increased stress on plants undergoing conditions conducive to growth resumption after an incomplete endodormancy release. It has been reported previously that unfavourable environmental conditions lead to developmental instability within the same individual (Freeman et al. 1999). Phenological asynchrony in clones undergoing stressful environmental conditions has also been reported by Alizoti et al. (2010) in Pinus nigra.

The results of Expt 3 confirmed the previously shown cumulative effect of short photoperiod on dormancy onset (Welling et al. 1997, Li et al. 2003), as increasing exposure to ShDs during the dormancy induction treatment decreased growth competence until endodormancy was reached. This effect was shown by a decrease in the percentage of budburst of unchilled buds as dormancy induction duration was extended from 30 to $60 \mathrm{~d}$ (Fig. 2). In addition, this behaviour was enhanced by low temperatures, which triggered a faster endodormancy than 
ShDs alone (the percentage of budburst in unchilled buds was lower after dormancy induction at $10^{\circ} \mathrm{C}$ than at $18^{\circ} \mathrm{C}$ ). The fact that in Expt 3 unchilled birch plants were able to resume growth, even if only partially, after receiving a dormancy induction treatment of 30 ShDs, but were dormant after $60 \mathrm{ShDs}$, suggested that the critical exposure to ShDs for endodormancy was between 30 and 60 . The low percentage of budburst $(12 \%)$ triggered by the low-temperature, short-dormancy induction treatment suggested that a $30 \mathrm{ShDs}$ period was close to the critical dormancy induction requirement if coupled with low temperatures, but a longer period was required at higher temperatures. Comparison of the phenology of Betula pubescens of different origins has shown that the critical daylength for growth cessation in $B$. pubescens varied depending on the latitude of origin and was generally longer for birch populations from more northerly sites (Håbjørg 1972). In our case, the observation that birch grew indefinitely in a $14 \mathrm{~h}$ photoperiod, but not in a $12 \mathrm{~h}$ photoperiod, suggested that the critical photoperiod for growth cessation and dormancy induction was between 12 and $14 \mathrm{~h}$ for this particular birch clone.

Endodormant birch plants (long dormancy induction at high temperature) receiving 50 chilling days at $10^{\circ} \mathrm{C}$ were able to grow once transferred to forcing conditions, with $67 \%$ budburst (Expt 3). On the other hand, birch plants receiving short dormancy induction at high temperature, which were not dormant at the time of transfer into the chilling treatments (the unchilled batch was still able to grow, as shown in Fig. 2), presumably completed the fulfilment of their dormancy induction requirements under the chilling treatments, and this delayed the start of chilling accumulation. As a result of this effectively shorter chilling time, trees were not able to grow when transferred to forcing conditions, with only $7 \%$ budburst observed. Thus, the chilling requirements of this birch clone are likely to be around or lower than $50 \mathrm{~d}$ at $10^{\circ} \mathrm{C}$.

This requirement is relatively small, and, in a northern temperate climate, it is likely to be fulfilled before the start of winter (21 December). This highlights the fact that, in natural conditions, endodormancy is necessary for overcoming autumn warm spells that could trigger growth before winter, while, during the coldest months, ecodormant buds rely on ShDs and low temperatures as environmental signals to prevent budburst. While a temperature of $10^{\circ} \mathrm{C}$ was still low enough to break endodormancy (Expts 3 \& 4), previous studies suggested that the upper threshold of active chilling temperatures is $<12^{\circ} \mathrm{C}$ for birch (Myking \& Heide 1995) and $15^{\circ} \mathrm{C}$ for Douglas fir (Harrington et al. 2010). Thus, the upper threshold for active chilling temperatures is likely to be between 10 and $15^{\circ} \mathrm{C}$.
Both the present results and previous studies (Sarvas 1974) support the use of a sigmoidal function for describing the rate of forcing in phenological models. However, the effect of temperatures $>30^{\circ} \mathrm{C}$ on bud growth during ecodormancy has rarely been tested; thus, it is unclear whether this response is truly sigmoidal or unimodal. This response is a critical trait to evaluate the risk of frost damage, since frost resistance is correlated to bud development and, to date, little information is available on its form for different species (Hänninen 2006). Therefore, the function parameterised in the present study (Fig. 1) provides important information when evaluating the impacts of climate warming on birch stands.

Warm and cold spells applied during ecodormancy at gradually increasing photoperiod length did not significantly affect the timing of budburst, when compared to plants receiving constant temperature and photoperiod. However, because the 2 factors were manipulated simultaneously, the interpretation of the results was confounded. Studies testing the effect of fluctuating day/night temperatures during forcing have provided contradictory results. While they promoted budburst in Pseudotuga menziesii (Campbell \& Sugano 1975) and Picea abies (Nienstaedt 1966), they did not affect Betula pubescens (Myking 1997). However, the different lengths of the temperature cycles applied in our study (8 and 16 d cycles vs. diurnal cycles), made a meaningful comparison with previous studies difficult.

\section{CONCLUSIONS}

The present study investigated the single effects and interaction of temperature and photoperiod on the rates of dormancy induction and release in birch through a series of inter-comparable experiments in controlled environments. On the basis of these results and previous studies, we propose a conceptual model of budburst for Betula pubescens as follows. (1) Endodormancy is mainly induced by ShDs, which act cumulatively and the effect of which is enhanced by low temperatures. The critical dormancy induction duration is slightly above $30 \mathrm{ShDs}$ at $10^{\circ} \mathrm{C}$, longer at higher temperatures. (2) Growth competence is absent or very low below a critical amount of chilling (exposure to temperatures $<10-15^{\circ} \mathrm{C}$ ), which is around $50 \mathrm{~d}$ at $10^{\circ} \mathrm{C}$. (3) The rate of chilling is solely dependent on temperature and not affected by photoperiod. (3) After fulfilment of the chilling requirement, increasing exposure to chilling temperatures progressively increases growth competence (and thus the growth rate at a given forcing temperature), decreasing the time to budburst down to a 
minimum (full growth competence). (4) During the progress from minimum to full growth competence, photoperiod above a critical threshold promotes budburst. This threshold is not constant, but decreases upon increasing chilling exposures. (5) The rate of forcing can be described by a positive sigmoidal function of mean daily temperature.

This model was formalized by Caffarra et al. (2011, this issue), who developed a predictive, process-based model of budburst for birch, the parameter values of which were partly fixed using the information from these experiments and partly fitted using existing phenological series of birch budburst.

The present findings bring to our attention the dynamic nature of the critical photoperiod necessary for growth resumption after partial chilling exposure. This response has not previously been reported, and is important for the development of biologically realistic models of budburst for this species. More experimental studies and molecular investigations could improve our knowledge of the mechanisms underlying this changing photoperiod sensitivity.

Nonetheless, the small sample size and the use of 1-node cuttings and newly rooted cuttings, as opposed to whole trees, suggest that caution is warranted when interpreting these results. Whereas rooted cuttings and trees grown from seeds show a similar phenology and growth rate in a number of tree species (Ritchie et al. 1992, Sasse \& Sands 1996, Jurasek 2007), 1-node cuttings might show shorter times to budburst compared to whole trees, due to the lack of correlative inhibition (Chao et al. 2007). In addition, as these experiments concerned a specific birch clone, the functions and thresholds parameterised in the present study should not be generalised to natural birch populations before their preliminary validation.

In order to obtain more precise information on the physiology of dormancy, more experimental studies are required on large numbers of trees, testing the effect of environmental drivers on the transition from a dormant to a non-dormant state. An understanding of these processes is fundamental to the development of realistic process-based models of tree phenology and in assessing the impacts of any future change in climate.

Acknowledgements. The authors thank Dr. Gerry Douglas and the plant nursery staff at the Irish Agricultural and Food Development Authority (Teagasc) (Dublin) for their technical help. We also acknowledge the support of the Irish Environmental Protection Agency under the Environmental RTDI Programme, 2000-2006, and Climate Change Impacts on Phenology; implications for terrestrial ecosystems. In addition, expert advice was provided through European COST Action 725 (Establishing a European Phenological Data Platform for Climatological Applications).

\section{LITERATURE CITED}

Alizoti PG, Kilimis K, Gallios P (2010) Temporal and spatial variation of flowering among Pinus nigra Arn. clones under changing climatic conditions. For Ecol Manag 259: 786-797

Arora R, Rowland LJ, Tanino K (2003) Induction and release of bud dormancy in woody perennials: a science comes of age. HortScience 38:911-921

Atkinson MD (1992) Biological flora of the British Isles: Betula pendula Roth (B. verrucosa Ehrh.) and B. pubescens Ehrh. J Ecol 80:837-870

Battey NH (2000) Aspects of seasonality. J Exp Bot 51: $1769-1780$

Caffarra A, Donnelly A, Chuine I (2011) Modelling the timing of Betula pubescens budburst. II. Integrating complex effects of photoperiod into process-based models. Clim Res 46:159-170

Campbell RK, Sugano AL (1975) Phenology of bud burst in Douglas-fir related to provenance, photoperiod, chilling, and flushing temperature. Bot Gaz 136:290-298

> Cannell MGR, Smith RI (1983) Thermal time, chill days and prediction of budburst in Picea sitchensis. J Appl Ecol 20: 951-963

Chao WS, Foley ME, Horvath DP, Anderson JV (2007) Signals regulating dormancy in vegetative buds. Int J Plant Dev Biol 1:49-56

Clifton-Brown JC, Jones MB (1999) Alteration of transpiration rate, by changing air vapour pressure deficit, influences leaf extension rate transiently in Miscanthus. J Exp Bot 50: 1393-1401

Couvillon GA, Erez A (1980) Rooting, survival, and development of several peach cultivars propagated from semihardwood cuttings. HortScience 15:41-43

Downs RJ, Borthwick HA (1956) Effects of photoperiod on growth of trees. Bot Gaz 117:310-326

Freeman DC, Graham JH, Tracy M, Emlen JM, Alados CL (1999) Developmental instability as a means of assessing stress in plants: a case study using electromagnetic fields and soybeans. Int J Plant Sci 160:157-166

$>$ Frewen BE, Chen THH, Howe GT, Davis J, Rohde A, Boerjan W, Bradshaw HD (2000) Quantitative trait loci and candidate gene mapping of bud set and bud flush in Populus. Genetics 154:837-845

Håbjørg A (1972) Effects of photoperiod and temperature on growth and development of three altitudinal and three latitudinal populations of Betula pubescens Ehrh. Meld Nor Landbrukshøgsk 57:1-27

Hänninen H (1990) Modelling dormancy release in trees from temperate and cool regions. In: Dixon RK, Warren WG (eds) Process modelling of forest growth responses to environmental stress. Timber Press, Portland, OR, p 159-165

Hänninen H (1995) Effects of climatic change on trees from cool and temperate regions: an ecophysiological approach to modelling of bud burst phenology. Can J Bot 73: 183-199

> Hänninen H (2006) Climate warming and the risk of frost damage to boreal trees: identification of critical ecophysiological traits. Tree Physiol 26:889-898

- Harrington CA, Gould PJ, St.Clair JB (2010) Modeling the effects of winter environment on dormancy release of Douglas-fir. For Ecol Manag 259:798-808

Hartmann HT, Kester DE, Davies FT Jr, Geneve LR (1997) Plant propagation: principles and practices, 6th edn. Prentice-Hall International Editions, Englewood Cliffs, NJ

$>$ Heide OM (1993) Daylength and thermal time responses of budburst during dormancy release in some northern 
deciduous trees. Physiol Plant 88:531-540

Heide OM (2003) High autumn temperature delays spring bud burst in boreal trees, counterbalancing the effect of climatic warming. Tree Physiol 23:931-936

Howe GT, Gardner G, Hackett WP, Furnier GR (1996) Phytochrome control of short-day-induced budset in black cottonwood. Physiol Plant 97:95-103

IPCC (Intergovernmental Panel on Climate Change) (2007) Climate change 2007: impacts, adaptation and vulnerability. Contribution of Working Group II to the IPCC. Cambridge University Press, Cambridge

Junttila O (1980) Effect of photoperiod and temperature on apical growth cessation in two ecotypes of Salix and Betula. Physiol Plant 48:347-352

Jurasek A (2007) Possibilities of using rooted cuttings of European beech (Fagus sylvatica L.) for stabilisation of forest ecosystem. J Sci 53:498-504

Kramer K (1994) Selecting a model to predict the onset of growth of Fagus sylvatica. J Appl Ecol 31:172-181

Landsberg JJ (1974) Apple fruit bud development and growth: analysis and an empirical model. Ann Bot (Lond) 38:1013-1023

Li C, Junttila O, Ernstsen A, Heino P, Palva ET (2003) Photoperiodic control of growth, cold acclimation and dormancy development in silver birch (Betula pendula) ecotypes. Physiol Plant 117:206-212

Lindman HR (1974) Analysis of variance in complex experimental designs. WH Freeman, Hillsdale, San Francisco, CA

Menzel A, Sparks TH, Estrella N, Koch E and others (2006) European phenological response to climate change matches the warming pattern. Glob Change Biol 12: 1969-1976

Murray MB, Cannell GR, Smith RI (1989) Date of budburst of fifteen tree species in Britain following climatic warming. J Appl Ecol 26:693-700

Myking T (1997) Effects of constant and fluctuating temperature on time to budburst in Betula pubescens and its relation to bud respiration. Trees (Berl) 12:107-112

Myking T, Heide OM (1995) Dormancy release and chilling requirement of buds of latitudinal ecotypes of Betula pendula and B. pubescens. Tree Physiol 15:697-704

Editorial responsibility: Tim Sparks, Cambridge, UK
Nienstaedt H (1966) Dormancy and dormancy release in white spruce. For Sci 12:374-384

Parmesan C, Yohe G (2003) A globally coherent fingerprint of climate change impacts across natural systems. Nature 421:37-42

Partanen J, Leinonen I, Repo T (2001) Effect of accumulated duration of the light period on bud burst in Norway spruce (Picea abies) of varying ages. Silva Fenn 35:111-117

Partanen J, Hanninen H, Hakkinen R (2005) Bud burst in Norway spruce (Picea abies): preliminary evidence for agespecific rest patterns. Trees Struct Funct 19:66-72

Peñuelas J, Filella I (2001) Phenology: responses to a warming world. Science 294:793-795

> Perry TO (1971) Dormancy of trees in winter. Science 171: 29-36

Quinn GP, Keough MJ (2002) Experimental design and data analysis for biologists. Cambridge University Press, Cambridge, $\mathrm{p} 221-261$

Ritchie GA, Tanaka Y, Duke SD (1992) Physiology and morphology of Douglas-fir rooted cuttings compared to seedlings and transplants. Tree Physiol 10:179-194

> Root TL, Price JT, Schneider SH, Rosenzweig D, Pounds JA (2003) Fingerprints of global warming on wild animals and plants. Nature 421:57-60

Sarvas R (1972) Investigations on the annual cycle of development of forest trees. Active period. Commun Inst For Fenn $76: 1-110$

Sarvas R (1974) Investigations on the annual cycle of development of forest trees. II. Autumn dormancy and winter dormancy. Commun Inst For Fenn 84:1-101

Sasse J, Sands R (1996) Comparative responses of cuttings and seedlings of Eucalyptus globulus to water stress. Tree Physiol 16:287-294

Sparks TH, Menzel A (2002) Observed changes in the seasons: an overview. Int J Climatol 22:1715-1725

Thomas B, Vince-Prue D (1997) Photoperiodism in plants. Academic Press, London

Welling A, Kaikuranta P, Rinne P (1997) Photoperiodic induction of dormancy and freezing tolerance in Betula pubescens. Involvement of $\mathrm{ABA}$ and dehydrins. Physiol Plant 100:119-112

Submitted: April 3, 2010; Accepted: December 9, 2010 Proofs received from author(s): February 23, 2011 